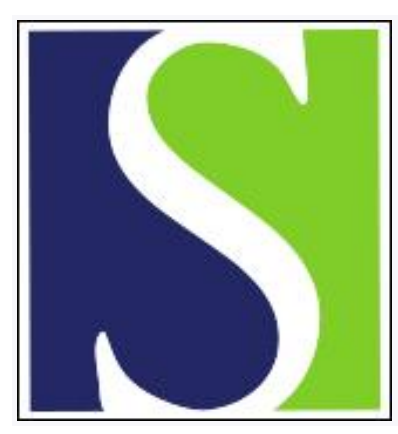

Scand J Work Environ Health 1978;4(2):159-166

https://doi.org/10.5271/sjweh.2713

Issue date: Jun 1978

\title{
Grip force in vibration disease.
}

by Färkkilä $M$

Key terms: 1-minute test; 5 -minute test; compression force; grip force; symptom group; vibration disease

This article in PubMed: www.ncbi.nlm.nih.gov/pubmed/684389

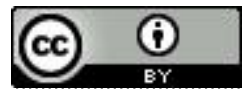




\title{
Grip force in vibration disease
}

\author{
by MARKUS FÄRKKILÄ, M.D. ${ }^{1}$
}

\begin{abstract}
FÄRKKILÄ, M. Grip force in vibration disease. Scand. j. work environ. \& health 4 (1978) 159-166. In this experiment the hand grip force of 58 persons was measured. The study was carried out during a compulsory health examination. The subjects compressed with their left hand for $5 \mathrm{~min}$ with fluctuating maximal force and with their right hand for $1 \mathrm{~min}$ with maximal constant force. The results were repeated with five different levels of vibration and without vibration. Individual forces varied in the 5-min experiment from 25 to $122 \mathrm{~N}$. The strongest subjects were in a group affected by white fingers, but with no claim of diminished grip force. The weakest forces were seen in the group subjectively most-affected by vibration disease. On the basis of this examination, it seems that in some workers longterm exposure to vibration causes a diminution in grip force, which is a constant phenomenon, and it does not only manifest itself during their work. During exposure to vibration the force reduced further from the resting level among the subjectively most-affected lumberjacks, but not in less-affected groups or in the reference group. No vibration frequency was found to be especially disadvantageous to grip force, and it was not possible to determine the normal limits of grip force.
\end{abstract}

Key words: compression force, 5-min test, 1-min test, symptom groups, vibration disease.

Vibration disease, a part of which is called traumatic vasospastic disease (TVD), is a syndrome among workers using vibrating tools. The disease affects blood vessels in fingers, and the nervous, bone, and muscle tissue of the upper extremities. In Finland $40 \%$ of the professional lumberjacks who used the chain saw had symptoms of the disease in 1972 (9). In connection with a previous study many lumberjacks claimed that the force of their hand grip was diminished (8). The subjective comprehension of the effect of grip force diminution on work ability was examined in a field study at Suomussalmi in northern Finland. Of the 187 lumberjacks examined, 36 suf-

1 Institute of Physiology, University of Helsinki, and Department of Physiology, Institute of Occupational Health, Vantaa, Finland.

Reprint requests to: Dr. Markus Färkkilä, Institute of Physiology, University of Helsinki, Siltavuorenpenger 20 a, SF-00170 Helsinki 17, Finland. fered from this symptom. Of these 36, seven considered their symptoms severe, and four said that their wages had been reduced because of a diminution of their grip force (10).

The physiological basis for the reduction of hand grip force is unknown. One explanation could be that the tonic vibration reflex (TVR) is activated by vibration and the muscle tone elevated continuously with a concomitant reduction in contractile force. Another possibility is a disturbance in muscle metabolism caused by insufficiency in blood circulation, and hence a reduction in compression force. Other possibilities could be a mechanical injury in the contractile proteins of muscle tissue caused by vibration or injuries in the peripheral nerves in muscles.

Marshall et al. (6) found that there is a reduction in the compression force of TVD patients after $4 \mathrm{~min}$ when blood circulation is prevented by the manchette of a sphygmomanometer. A corresponding re- 
Table 1. Comparison of the subject groups.

\begin{tabular}{|c|c|c|c|c|c|c|}
\hline Group & $\begin{array}{l}\text { Grip } \\
\text { force } \\
\text { reduced }\end{array}$ & $\begin{array}{l}\text { White } \\
\text { fingers }\end{array}$ & $\begin{array}{l}\text { Mean age } \\
\pm \mathrm{SD} \\
\text { (years) }\end{array}$ & $\begin{array}{l}\text { Mean exposure } \\
\text { time } \\
\text { (h and range) }\end{array}$ & $\begin{array}{l}\text { Number } \\
\text { of } \\
\text { subjects }\end{array}$ & Remarks \\
\hline $\mathrm{I}$ & No & No & $37.1 \pm 4.7$ & $\begin{array}{c}8,720 \\
(3,900-12,800)\end{array}$ & 6 & 一 \\
\hline II & No & Yes & $39.7 \pm 7.6$ & $\begin{array}{c}12,100 \\
(7,500-26,800)\end{array}$ & 16 & $\begin{array}{l}\text { Cold provocation test done } \\
\text { for each, positive in } 75 \%\end{array}$ \\
\hline III & Yes & No & $39.8 \pm 6.5$ & $\begin{array}{c}11,650 \\
(4,200-22,800)\end{array}$ & 15 & $\begin{array}{l}\text { Anamnestic reduction in } \\
\text { grip force: } 53 \% \text { of the sub- } \\
\text { jects bilaterally, others uni- } \\
\text { laterally (left) }\end{array}$ \\
\hline IV & Yes & Yes & $44.4 \pm 7.4$ & $\begin{array}{c}11,840 \\
(3,900-12,800)\end{array}$ & 14 & - \\
\hline $\mathrm{V}$ & No & No & $28.4 \pm 9.4$ & - & 7 & Reference group \\
\hline Total & & & $39.2 \pm 7.2$ & $\begin{array}{c}10,130 \\
(3,900-26,800)\end{array}$ & 58 & 一 \\
\hline
\end{tabular}

duction was noted after $10 \mathrm{~min}$ in a healthy reference group.

So far the diagnosis of vibration disease has been based on anamnestic information of white fingers and the relationship of the symptoms to occupation. Therefore it is difficult to estimate the severity of the disease, and many indexes have been proposed for this purpose $(9,11)$. The present study focuses on the grip force symptoms.

\section{SUBJECTS}

In the spring of 1975 about 230 professional lumberjacks from the region of Suomussalmi were examined (10). The lumberjacks had come to the annual health examination, which is compulsory in Finland. About 20 lumberjacks were examined daily, of whom I selected five to nine subjects for grip force measurement on the basis of symptoms of white fingers, reduced compression force, and numbness of hands. In order to investigate separately the roles of vibration exposure and vasospastic attacks on grip force, I grouped the lumberjacks and referents according to the following criteria:

Group I: professional lumberjacks who had no symptoms of vibration disease.

Group II: professional lumberjacks who had no subjective change in grip force, but had had white fingers during the past two years.

Group III: professional lumberjacks who had a subjectively diminished grip force unilaterally or bilaterally but had never had any attacks of white fingers.

Group IV: professional lumberjacks who had a subjectively diminished grip force and white fingers.

Group V: a reference group; it consisted of men with the same employer (Metsähallitus), e.g., harvester drivers, farmers, who had never used the chain saw or other vibrating tools professionally.

The grip force of 58 persons was measured. The number, ages, and exposure times of the subjects are presented in table 1. All the subjects examined were righthanded, and they did not have previous lesions in their hands or arms.

\section{METHODS}

To evoke vibration in the hand, I used a dynamic shaker (Ling 403). For the measurement of grip force, the handle of the shaker consisted of two metal bars (diameter $25 \mathrm{~mm}$, length $1,400 \mathrm{~mm}$ ) with strain-gauges (Honeywell-Selcom). The output voltage of the strain-gauges was recorded with an inkwriter (Watanabe 
H611). The vibrator was driven by sinusoidal voltage. The acceleration level and frequency were changed step by step in the following way: acceleration level was kept at $5 \mathrm{~g}$ (rms values) when the frequencies were 30 and $60 \mathrm{~Hz}$, and at $10 \mathrm{~g}$ when the frequencies were 100,200 and $400 \mathrm{~Hz}$. (The lower acceleration level was chosen to protect the vibrator.) The test subject sat on a chair while he leaned on a table with one hand and compressed the handle with the other. The wrist and lower arm composed a flexion angle of $150^{\circ}$. The elbow was slightly flexed. The axis of the vibration was linear to the lower arm.

Each subject was tested in two experiments. Always in the first experiment the subject pressed the handle with his left hand repeatedly with maximal force in pace with the strokes of a metronome. The frequency was one grip in $5 \mathrm{~s}$; the compression lasted for $2.5 \mathrm{~s}$ and was followed by a pause for another $2.5 \mathrm{~s}$. This rhythmic compressing lasted for $5 \mathrm{~min}$. This 5 -min test of compressions was repeated six times (interval between the trials $10 \mathrm{~min}$ ), once without vibration and with vibration at frequencies $30,60,100,200$, and $400 \mathrm{~Hz}$. In the second experiment the maximal continuous grip force was measured during 1 min with the right hand once without vibration and with vibration of the same five frequencies (interval between the trials $2 \mathrm{~min}$ ). The blood flow remained unaffected in the 5-min test, but the 1min test represented anaerobic muscle work (5). Both experiments were performed simultaneously by two subjects, and the starting frequency was decided by lot. The following frequencies were then an increase with one dose. To avoid rivalry between the subjects, I did not allow the subjects to reveal their results to each other, and they were not aware of their performance during the test. The examination room temperature was between $18-20^{\circ} \mathrm{C}$, and the skin temperature of the arm was checked before the test.

The vibration exposure time was counted from the subjects' responses to questions on how many hours they used the chain saw daily, how many days they worked in a month, how many months they worked in a year, and how many years they had worked in such a manner.

\section{RESULTS}

\section{Individual recordings}

In the 5-min experiment there was individual variation in the shape of the successive grip forces (fig. 1). These compression profiles were quite individual, and interindividual differences were larger than the intraindividual ones. Some fluctuation was noted in the level of the force during the $5 \mathrm{~min}$. The grip force gradually decreased grip by grip until there suddenly came a new wave of grip force, which again decreased. The fluctuations were the most marked in the beginning of the recordings. There were similar features in the 1-min test. To some degree the subjects could estimate the test time and adapt their forces so that there often appeared an attempt to make a final effort, seen in the recording as an "end-spike" (fig. 2).

These oscillations in grip force were also noted in recordings from subjects whose grip forces were lower, which indicate that also these subjects were trying to compress with maximal force. The arithmetic mean force of the plate values was calculated for all of the 60 grips for each subject at every frequency. In the 5 -min test the mean forces varied between 25 and $122 \mathrm{~N}$. However, for each individual the forces were quite constant in repeated trials $(<20 \mathrm{~N})$. Fig. 3 presents the distribution of the mean grip forces of the left hand. The results were similar for the right hand.

\section{Grip forces in different groups}

Fig. 3 shows that the material examined consisted of both strong- and weakhanded men. However, the lowest forces were recorded in group III, which complained of diminished grip force, whereas forces exceeding $100 \mathrm{~N}$ were more common in group II, the members of which had white fingers. The subjects in group IV were the weakest. When the forces were compared between the groups, the strongest forces were found in the reference group (V) and in the white-finger group (II). The forces in the asymptomatic vibration-exposed group (I) were the same as in group III. 


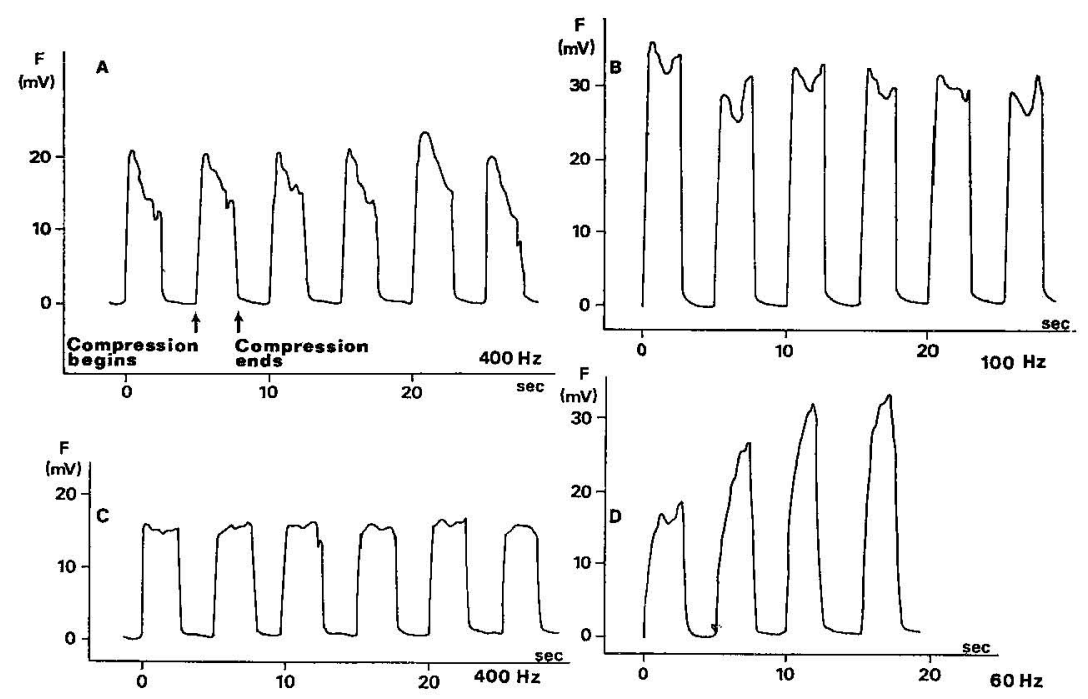

Fig. 1. Examples of the grip force profiles in a 5-min experiment with the left hand. (A = lumberjack, 39 years old, sawing time 7,600 h, who suffered from white fingers and had a grip force that was subjectively diminished; the recording is $4 \mathrm{~min}$ after the beginning, vibration 400 $\mathrm{Hz}, 10 \mathrm{~g}$. B = lumberjack, 49 years old, sawing time 13,100 $\mathrm{h}$, who suffered from white fingers only; the recording is $30 \mathrm{~s}$ after the beginning, vibration $100 \mathrm{~Hz}, 10 \mathrm{~g}$. C = lumberjack, 30 years old, sawing time 13,100 h, who suffered from white fingers, a subjectively diminished grip force, and numbness in the hands; the recording is $4 \mathrm{~min}$ and $30 \mathrm{~s}$ after the beginning, vibration 400 $\mathrm{Hz}, 10 \mathrm{~g}$. D = farmer, 33 years old, who had never used the chain saw professionally and who had no symptoms; the recording is 2 min after the beginning, vibration $60 \mathrm{~Hz}, 5 \mathrm{~g}$.)

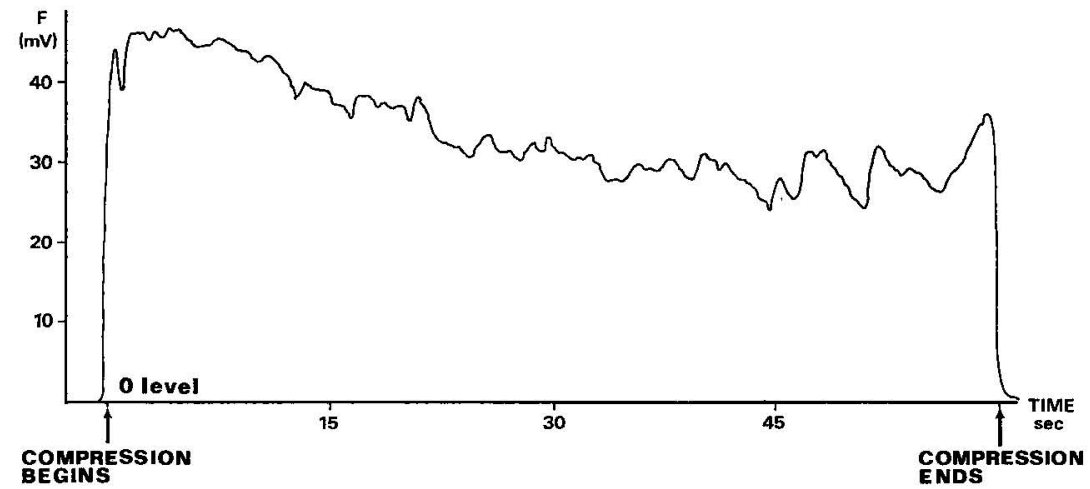

Fig. 2. Typical recording in a 1-min experiment with the right hand of a 43-year-old harvester driver who had never used a chain saw and had no symptoms.

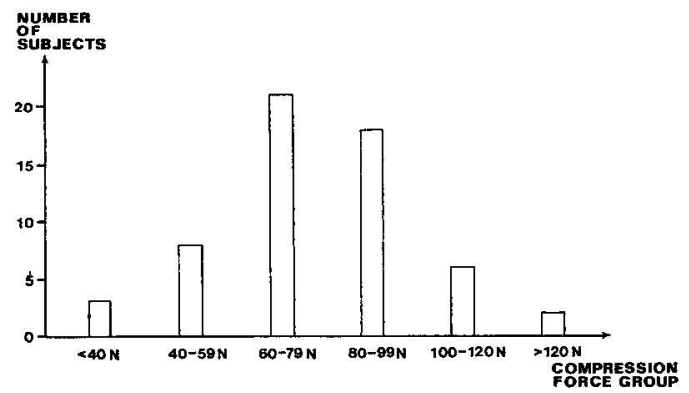

Fig. 3. The distribution of the 58 subjects examined according to their left-hand grip force. 


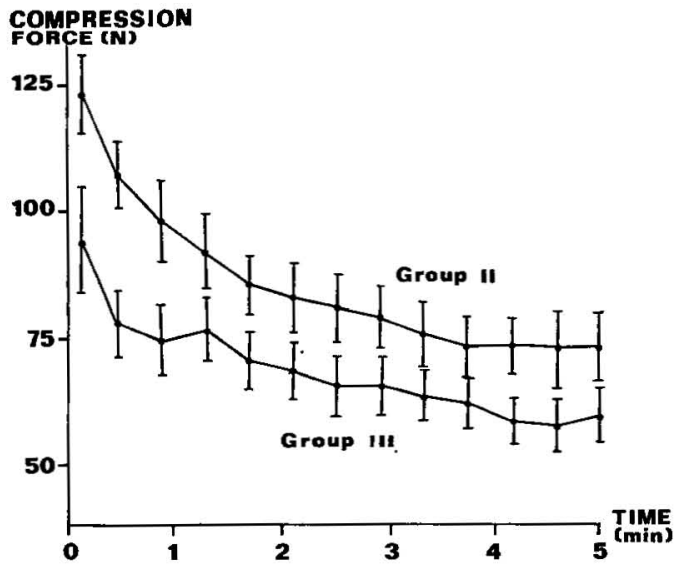

Fig. 4. Five-minute experiment with the left hand without vibration. The means and standard errors of the means of the grip forces in groups II and III. The mean forces of group II were continuously stronger than the those of group III, statistically highly significant, $\mathrm{p}<$ 0.005. (One-way analysis of variance, multiple $t$ method).

In the 5-min experiments the forces in the reference group were of the same magnitude as in group II. The forces in group III were lower at every vibration frequency when compared to those in group II, which is presented in fig. 4 (multiple $t$ test, $\mathrm{p}<$ $0.005)$.

In the 1-min experiments the forces of the referents were higher than those of the others, including the white-finger group (II) (multiple $t$ test, $\mathrm{p}<0.01$ ).

The shape of the curves was similar for all groups. The force decreased by about $40 \%$ of its starting value during the 5min time period. The result has been calculated from the mean of all the frequencies of all the 58 subjects tested. Over half of the reduction in force took place during the first minute. During the second minute the forces diminished another $20 \%$ out of the whole reduction, and after that $10 \%$ in a minute. In the 5-min experiment, the force decreased from 130 to $64 \mathrm{~N}$ in the reference group. In the subjectively greatly affected group IV the forces decreased from 85 to $49 \mathrm{~N}$ in the same experiment. The results have been calculated from recordings without vibration, but the results were alike during vibration ex- posure. The reductions in other groups were respectively: group III from 95 to 59 $\mathrm{N}$ and group II from 123 to $76 \mathrm{~N}$.

\section{Effect of vibration on grip force}

In general the forces were somewhat weaker during vibration than without it. The force of the most affected subjects (group IV) was reduced as compared with the referents (fig. 5), and during vibration exposure the force diminished still further (fig. 6) (multiple $t$ test, $\mathrm{p}<0.01$ ).

The result was similar in the 1-min experiment. This phenomenon was not noticed in other groups.

The grip forces diminished in the same way at every vibration frequency, which was noted during the $5 \mathrm{~min}$. Fig. 7 shows the mean results of the 58 subjects examined at different frequencies. In the 1min experiment of the right hand there was a significant difference $(p<0.01)$ between the controls and those with exposure to vibration at $30 \mathrm{~Hz}$ frequency. At other frequencies the differences between the groups were very small.

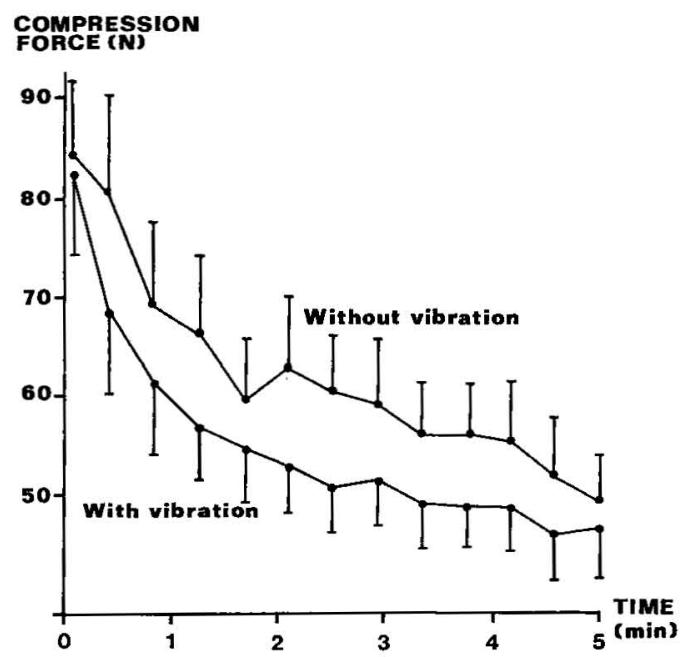

Fig. 5. Five-minute experiment with the left hand without vibration. Means and standard errors of the means of the grip forces in groups IV and V. The differences in grip forces were statistically highly significant $(\mathrm{p}<0.005)$. 


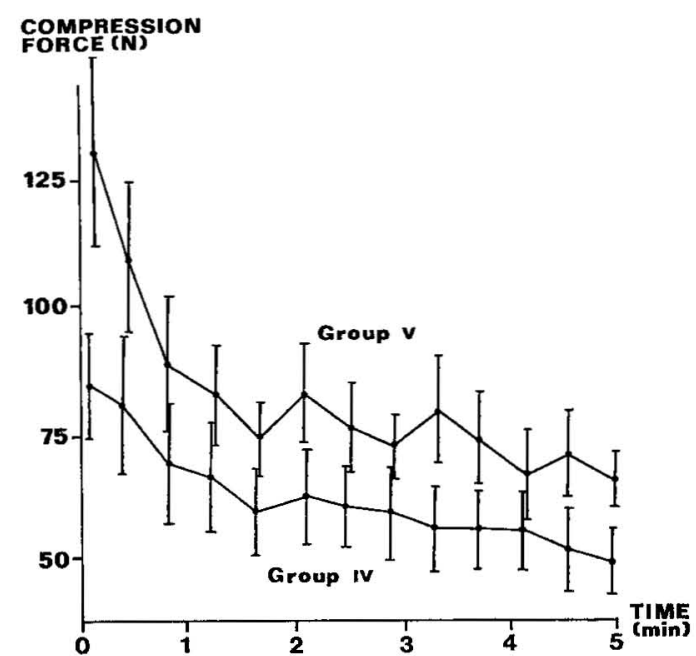

Fig. 6. Reduction in grip force caused by vibration in group IV (most affected). Means and standard errors. The vibration values were computed from all five frequencies tested. The difference was statistically significant $(p<$ $0.01)$.

Correlation between grip force, vibration duration and the experimental procedure

The grip force in the 5-min test did not depend on the time of occupational vibration exposure. The linear regression of grip force and occupational vibration exposure in the right-hand test is seen in fig. 8. Everyone who complained of diminished force had sawn at least 6,000 h. The subjectively most-affected subjects with their grip force symptoms (10) had sawn about $11,100 \mathrm{~h}$. Their mean age was 42.8 years, and the mean age of all the subjects was 39.2 years. The mean latency time before vasospastic disorders for chain

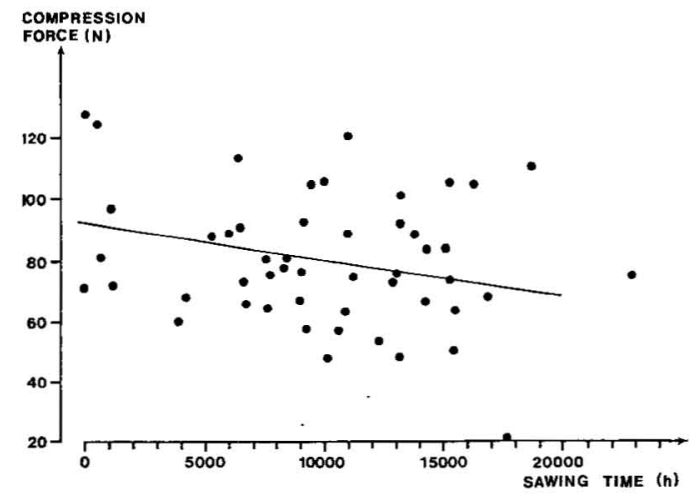

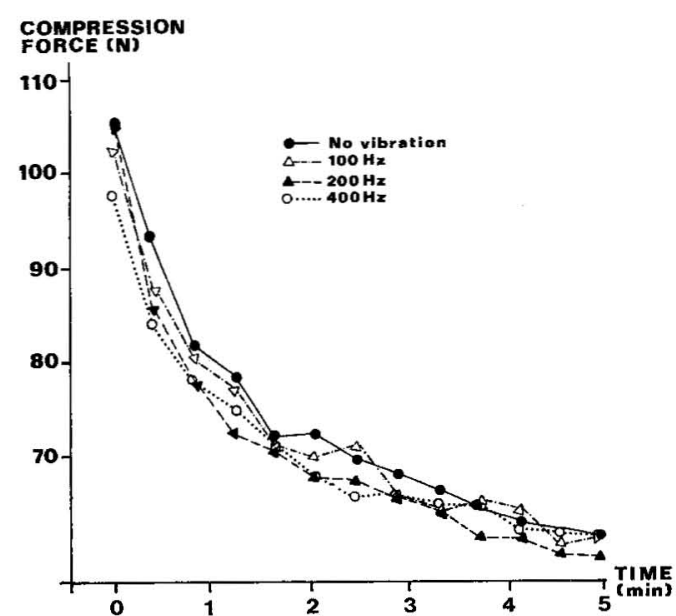

Fig. 7. Mean grip forces of all the 58 subjects in the 5 -min experiment without vibration and with vibration at 100,200 and $400 \mathrm{~Hz}$. The differences were statistically nonsignificant $(p<$ 0.25).

saw operators is $5,600 \mathrm{~h}$ (9). On the basis of these results it seems that grip force diminution is correlated positively to vibration exposure, and the result is not an effect of weakening of the hands during ageing. The motivation of the subjects to compress did not affect the results in these experiments, which were repeated six times. When the mean forces in compression order of all the 58 subjects were compared, only a slight reduction was found from the first experiment to the sixth. The mean force at the frequency first tested was $85 \mathrm{~N}$, in the second test $79 \mathrm{~N}$, in the third $74 \mathrm{~N}$, in the fourth $75 \mathrm{~N}$, in the fifth $74 \mathrm{~N}$ and in the sixth one $72 \mathrm{~N}$.

Fig. 8. Dependence of the mean grip forces and duration of vibration exposure. One-minute experiment, right hand. The mean force during all 1-min tests of each subject. In the statistical analysis there was no simple linear regression of grip force on exposure time, least square method. 


\section{DISCUSSION}

The test subjects were chosen according to history, and the test schedule was decided by lot. Those anamnestically weakhanded considered their forces to be diminished either unilaterally or bilaterally. The symptom was bilateral in $53 \%$ of the subjects, and, if unilateral, then the left hand was always affected.

The measurements did not correlate with the anamnestic unilateral diminished force. The compression force profiles noticed in individual curves were not typical of any group or the force used. In most cases the compression force profile was of the same type during the 5-min test. The shapes of the profiles reflected more the reaction velocity, the intensity of the performance, and the motivation of the subject. Fluctuations occurred in the compression force during both experiments, and I considered them as a sign of intensity in the grip force. The more fluctuations, the nearer the subject was to compressing with his maximal force. It was very difficult to say what is a "normal" force. The deviation in the different groups was large, and even intraindividual variation was remarkable, although smaller than the interindividual variation. The grip force measurements were affected by the motivation of the test subject, but this fact did not have an effect on the results. The curves were very much of the same shape in repeated trials, and the forces decreased only slightly from the first to the sixth registration. The lumberjacks were motivated by their work, and they were not looking for any social advantages through this experiment. According to the measurement it seems that the history can be relied on, at least in this kind of health examination.

Previous experience with compression force changes is controversial. Teléky (12) described hypothenar muscle atrophy and atrophy of the small muscles of the palm to be associated with exposure to vibration. The grip force was found to be decreased anamnestically in a field study at Suomussalmi (10). Hellström and Lange-Andersen (4) measured maximal isometric compression force among referents and a group exposed to vibration. They could not find differences between these groups. They concluded that probably the decrease in grip force is not associated with vibration disease. Negative results of the same kind have been published by Agate (1) and Ashe et al. (2).

The activation of the tonic vibration reflexes (TVR) could be the cause of diminished force. For the activation of TVR a sufficiently high amplitude $(1-2 \mathrm{~mm})$ is essential, and TVR is considered to be especially sensitive at vibration frequencies from 40 to $700 \mathrm{~Hz}$. The dominant frequency of devices causing vibration disease is in the same range. In addition exposure to cold has been considered to increase the intensity of TVR (3). According to this examination, it seems that the activation of TVR is not responsible for the decrease in grip force during vibration in acute exposure, as in this experiment. If TVR would have been activated, the forces should have increased in the beginning of the recordings, but invariably the forces diminished after the starting grip. But the decrease can be a chronic effect of TVR.

The diminished blood flow in the hand muscles could be the cause of the diminished grip force. Teléky (12) considered that the atrophy of hypothenar and palmar muscles is due to microtraumas of the blood vessels and mechanical compression. His theory is supported by the observation that the atrophies do not follow the boundaries of nerve branches. In this examination I found that the forces between group II and the reference group were equal in the 5-min test, and the forces of group II were larger than those of group III (fig. 4). Okada et al. (7) measured muscle blood flow among subjects with Raynaud's phenomenon and compared it with that in reference subjects. They found that Raynaud's phenomenon was associated with diminished blood flow in palmar muscles. Thus it seems that the diminished blood flow is not responsible for the reduced grip force, and the reduced compression force is not associated with white fingers. The force was reduced in group IV in comparison with group II, but this observation does not reveal the etiology of the mechanism of force reduction. It only shows that the more affected the subjects the smaller the forces.

Another possible mechanism could be 
lesions of peripheral nerves in muscle tissue or disturbances in the function of muscle contractile proteins. Hellström and Lange-Andersen (4) concluded in their examination that the atrophies, if they do exist, are due to lesions in peripheral nerves. The present examination does not clarify these reasons.

According to my results it seems that the vasospastic symptoms and diminished compression force have different pathophysical mechanisms. This conclusion is supported by the equal compression forces of group II and the referents, and by the diminished compression force in group III without any vasospastic symptoms. Besides, everyone suffering from diminished compression force had used the chain saw more than $6,000 \mathrm{~h}$, and the four lumberjacks most affected with grip force symptoms had a mean vibration exposure of 11,100 hours. Therefore there was a correlation between vibration exposure and compression force symptoms.

It seems that among some workers longterm exposure to vibration causes a diminution in grip force which is a constant phenomenon, and it does not only manifest itself during their work. During exposure to vibration the force reduced further in the group of subjectively mostaffected lumberjacks (group IV). In the other groups this phenomenon was not observable. No vibration frequency was found to be particularly harmful to grip force in any of the groups examined, an observation important for the planning of ergonomically optimal vibrating tools.

It is possible that vibration disease manifests itself in different ways in different people. In some workers vibration causes a vasospastic disease, and in others the symptoms of diminished grip force or numbness dominate.

\section{REFERENCES}

1. AGATE, J. N. An outbreak of cases of Raynaud's phenomenon of occupational origin. Br. j. ind. med. 6 (1949) 144-163.

2. ASHE, W. F., COOK, W. T. and OLD, J. W. Raynaud's phenomenon of occupational origin. Arch. environ. health 5 (1962) 333343.

3. EKLUND, G. and HAGBARTH, K.-E. Normal variability of tonic vibration reflexes in man. Exp. neurol. 16 (1966) 80-92.

4. HELLSTROM, B. and LANGE-ANDERSEN, K. Vibration injuries in Norwegian forest workers. Br. j. ind. med. 29 (1972) $255-263$.

5. HUMPREYS, P. W. and LIND, A. R. The blood flow through active and inactive muscles of the forearm during sustained handgrip contractions. J. physiol. 166 (1963) $120-135$.

6. MARSHALL, J., POOLE, E. B. and REYNARD, W. A. Raynaud's phenomenon due to vibrating tools. Lancet 1 (1954) 11511156.

7. OKADA, A., YAMASHITA, T., NAGANO, C., IKEDA, T., YACHI, A. and SHIBATA, S. Studies on on the diagnosis and pathogenesis of Raynaud's phenomenon of occupational origin. Br. j. ind. med. 28 (1971) $353-357$.

8. PYYKKO, I. The prevalence and symptoms of traumatic vasospastic disease among lumberjacks in Finland: A field study. Work-environ.-health 11 (1974) 118-131.

9. PYYKKÖ, I. Traumaattinen vasospastinen sairaus suomalaisilla metsureilla: Esiintyminen, oireet ja fysiologinen syntymekanismi (Työterveyslaitoksen tutkimuksia no. 88). Institute of Occupational Health, Helsiniki 1974. $64 \mathrm{p}$.

10. PYYKKO, I., SAIRANEN, E., KORHONEN, O., FÄRKKILÄ, M., OJALA, J.-P. and RUOKONEN, E. The vibration disease among forest workers. Suom. lääkärilehti 31 (1976) 2791-2797.

11. TAYLOR, W. PELMEAR, P. L. and PEARSON, J. Raynaud's phenomenon in forestry chain saw operators. In: W. TAYLOR (ed.), The vibration syndrome. Academic Press, London 1974, pp. 121-139.

12. TELEKY, L. Pneumatic tools. Occup. health 1 (1938) $1-12$. 